\title{
Le rapport de gestion 2008 est arrivé
}

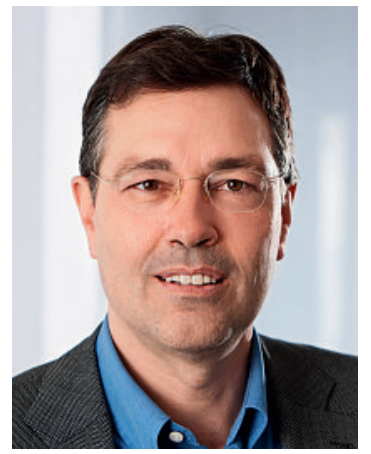

Daniel Herzog
Vous trouverez, en annexe au présent numéro du BMS, le rapport de gestion 2008 de la FMH. En le parcourant, vous serez frappé par l'activité intense et diversifiée de la FMH au cours de l'année passée sous revue. Sur le plan politique, la FMH a notamment combattu avec succès les attaques contre l'obligation de contracter grâce à une action concertée avec les autres associations des «professions bleues». Par une majorité de $70 \%$

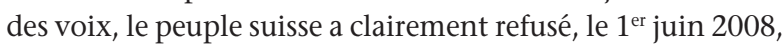
l'article constitutionnel visant à renforcer le pouvoir des caisses-maladie. Il en résulte que les initiatives politiques demandant la levée de l'obligation de contracter devraient avoir des difficultés à s'imposer à l'avenir.

\section{Le corps médical a combattu avec succès \\ les attaques contre l'obligation de contracter}

Les divers projets menés par la FMH en 2008 furent passionnants et couronnés de succès: ainsi, grâce à d'importants travaux préparatoires, la carte de professionnel de santé de la FMH est sur le point d'être délivrée, et le Département pour la formation prégraduée, postgraduée et continue s'est autonomisé pour devenir l'Institut suisse pour la formation médicale postgraduée et continue (ISFM). Le présent rapport vous fournira des informations détaillées à ce sujet ainsi que sur tous nos autres projets.

En ce qui concerne l'organisation de la FMH, 2008 fut marqué par une élection générale qui entraîna une réduction de la taille du Comité central (CC). Parmi les 11 membres présents initialement, cinq sont restés, et quatre ont été nou- vellement élus par la Chambre médicale. Le nouveau Comité central pourra toujours compter sur l'expérience de ses membres tout en étant à même de travailler de manière encore plus efficace grâce à une structure allégée.

\section{La FMH a enregistré une augmentation d'environ $2,7 \%$ du nombre de ses membres}

$\mathrm{Au}$ cours des premiers mois de son mandat, l'une des tâches de ce Comité renouvelé a consisté à élaborer les objectifs stratégiques de la FMH pour la législature 2008-2012, qui ont ensuite été approuvés par la Chambre médicale extraordinaire de décembre 2008. Le CC dispose ainsi d'un cadre d'action qui fixe la voie à suivre et légitime ses activités.

Il semblerait que la FMH soit une organisation professionnelle attrayante, si l'on en croit l'augmentation de 2,7\% du nombre de membres, qui se montait à 34547 membres à la fin 2008. La demande de titres et de formations approfondies ne semble pas non plus fléchir, tant il est vrai que l'on note là aussi une forte croissance.

Sur le plan financier, l'année s'est soldée positivement malgré une baisse des cotisations par rapport à l'année précédente. La FMH a clos l'année avec un bénéfice confortable dû principalement à l'augmentation du nombre de demandes de titres et de formations approfondies dans le domaine de la formation prégraduée, postgraduée et continue.

Dans l'ensemble, il s'est agi d'une année très réussie. La lecture du rapport de gestion - doublée du plaisir de vous laisser fasciner par les images de microorganismes qui agrémentent ses pages cette année - ne manqueront pas de vous en convaincre.

Je vous souhaite une agréable lecture.

Daniel Herzog, lic. en droit, MHA, secrétaire général de la FMH 